\title{
A transculturação em $O$ outro pé da sereia: Uma análise da filosofia do romance de Mia Couto.
}

\author{
Blanca Cebollero Otín ${ }^{1}$
}

RESUMO: A analise do romance $O$ outro pé da sereia apartir do conceito de transculturação narrativa que desenvolveu Ángel Rama permite fazer a comparação da narrativa deste escritor moçambicano com narrativas brasileiras e hispano-americanas. A analise do romance desenvolve a comparação nos três aspectos que, segundo Rama, são fundamentais para falar em transculturação narrativa: a língua, a estruturação literária e a cosmovisão.

ABSTRACT: The analysis of the novel $O$ outro pé da sereia from the concept of narrative transculturation that Ángel Rama developed allows the comparison of the narrative of this Mozambican writer with Brazilian and Spanish American narratives. The analysis of the novel develops the comparison into three aspects that, according to Rama, are essential to talk about narrative transculturation: language, literary structure and world-view.

PALAVRAS-CHAVE: Transculturação, linguagem, estrutura, mito.

KEYWORDS: Transculturation, language, structure, myth.

Na sua obra de ficção o escritor moçambicano Mia Couto joga freqüentemente com a linguagem e cria neologismos, altera a sintaxe (embora não o faça ao nível e intensidade de um dos seus mestres, o brasileiro João Guimarães Rosa), utiliza a tradição oral e os provérbios. A analise do romance $O$ outro pé da sereia apartir do conceito de transculturação narrativa que desenvolveu Ángel Rama e que aplicou a escritores como João Guimarães Rosa, Juan Rulfo, José María Arguedas ou Gabriel García Márquez.

\footnotetext{
${ }^{1}$ Mestranda em Literaturas brasileiras e africanas de língua portuguesa. Faculdade de Letras da Universidade de Lisboa, Portugal. Pesquisa: "Linguagem e poder em Guimarães Rosa e Juan Rulfo".

E-mail: bladamara@yahoo.es
} 
O conceito de transculturação foi usado por Fernando Ortiz no âmbito da antropologia como resposta ao conceito mais restrictivo de aculturação:

Entendemos que o vocábulo "transculturação" expressa melhor as diferentes fases do processo transitivo de uma cultura a outra, porque este não consiste apenas em adquirir uma cultura, que é o que a rigor indica o vocábulo anglo-americano "aculturação", mas implica também necessariamente a perda ou o desligamento de uma cultura precedente, o que poderia ser chamado de uma parcial "desaculturação", e, além disso, significa a conseqüente criação de novos fenômenos culturais que poderiam ser denominados "neoculturação"2.

Ángel Rama utiliza este conceito para realizar a análise de determinadas formas narrativas e elabora o conceito de transculturação narrativa que já não é antropológico senão literário. Ainda que este conceito de transculturação narrativa tenha sido aplicado por Ángel Rama às narrativas latinoamericanas, é possivel analisar o romance $O$ pé da sereia de Mia Couto a partir dele para comprovar quais os limites do conceito e quais as conclusões de estudar sob esta perspectiva um romance da literatura moçambicana. Portanto, vamos considerar aqueles três aspectos que, segundo Rama, são fundamentais para falar em transculturação narrativa: a língua, a estruturação literária e a cosmovisão.

\section{A lingua}

Segundo Angel Rama as modificações que introduzem na língua os escritores que ele nomeia como transculturadores são relevantes em relação ao uso da língua dos escritores regionalistas latinoamericanos anteriores. Estes escritores alternavam a língua culta com a fala dialetal dos personagens rurais para produzirem um efeito de ambientação realista. O uso de um léxico regional, de formações fonéticas e construções sintáticas locais eram marcados através de recursos como

2 Fernando Ortiz, Contrapunteo cubano del tabaco y el azúcar, Havana, Consejo Nacional de Cultura, 1963, citado em Ángel Rama, Literatura e cultura na América Latina, São Paulo, Editora Universidade de São Paulo, 2001, p. 216. 
o uso de aspas, de glossários e apêndices explicativos. Portanto, eles marcavam a diferença dessas línguas locais ou regionais e até condenavam-nas explicitamente nalguns romances e avaliavam-nas como incorrectas em relação à norma lingüística imperante. Isto tudo supõe uma determinada posição do escritor relativamente à língua.

As mudanças no uso da língua dos escritores transculturadores consistiram em: a redução dos dialetismos e termos americanos; a substituição da fala popular pela fala americana própria de cada escritor; a eliminação dos glossários por pensarem que essas palavras podem ser percebidas através do contexto lingüístico; a diminuição da distância entre a fala do narrador e a dos personagens; e também a criação de uma língua artificial e literária para as falas autóctones dos personagens. Estas mudanças no uso da língua implicam mudanças na posição crítica e ideológica do escritor.

Ao analisar $O$ outro pé da sereia é possível verificar que, como acontece na escrita dos transculturadores latino-americanos, não há distância entre a fala dos personagens e a fala do narrador além da diferença própria do discurso directo. Portanto, a incorporação de vocábulos pertencentes ao léxico local vê-se não só na fala dos personagens - por exemplo em “ O que fazia com esse muana?”3 ou “Sou quizumba para mexer em ossos já mortos?” (PS, p. 49) —, mas também no discurso do narrador - "O magaíça depôs o caixão na areia"(PS, p. 90) ou "Era uma canoa feita de um tronco de mbawa e estava ocultada entre os caniços da margem” (PS, p. 77). Aliás, a duplicidade estrutural das histórias e dos tempos narrativos possibilita a introdução dalguns termos da língua goense, por exemplo, no diálogo entre Dia e Nimi Nsundi, ela diz: "Você não passa de um firngi!" (PS, p. 130).

No entanto, a pesar de o romance não ter um glossário final com os termos locais todos, Mia Couto introduz explicações em notas de rodapé marcadas no texto através do signo (*), por exemplo, “(*) Hakata:

3 Edição utilizada: Mia Couto, O outro pé da sereia, Lisboa, Caminho, 2006, p. 119. (Todas as referências e citações desta edição passam a ser indicadas com PS). 
sementes usadas nas práticas de adivinhação” (PS, p. 89). Em conseqüência, no que diz respeito à estas explicações Mia Couto afastase da idéia dos escritores transculturadores relativa à possibilidade de deduzir o significado do termo local pelo contexto lingüístico e, portanto, não salientar a diferença desses termos através de signo nenhum.

Mas nem por o uso destas explicações lexicais o discurso narrativo de Mia Couto torna-se um discurso que marca a sua diferença e coloca a língua portuguesa numa situação de superioridade lingüística relativamente às línguas indianas e moçambicanas. Uma prova disto é o facto de o uso da língua neste romance concordar com as outras características do uso da língua feito pelos escritores transculturadores. Assim, neste romance há também uma redução de termos locais relativamente àqueles romances que incorporam um glossário final. E, sobretudo, neste romance como em outros anteriores, Mia Couto cria uma língua literária e elaborada que substitui a fala autóctone dos personagens.

$\mathrm{Na}$ elaboração desta língua literária serve-se de vários recursos lingüísticos: a criação de neologismos, o uso de provérbios e a alteração criativa dos mesmos são os mais importantes. Exemplo de neologismos é "crespuscalado", Algunas alterações literárias de provérbios são "Eu conheço-a como a palma da minha mãe" (PS, p. 84) ou "É que isto, em Vila Longe, vai de animal a pior” (PS, p. 105). Também o uso poético da língua através da criação de imagens e metáforas é um dos recursos mais usados por Mia Couto. Um exemplo deste uso poético aparece no primeiro capítulo do romance quando Mwadia diz: “A lua hoje está cheia de pólen" (PS, p. 26) para simbolizar a sua saudade.

No uso destes procedimentos percebe-se a influência do escritor brasileiro Guimarães Rosa e é também o objetivo deste escritor de revitalizar a linguagem que procura atingir Mia Couto. O carácter poético da prosa do Guimarães Rosa provém da idéia que ele tem da linguagem: a criação poética é a construção de uma nova visão do mundo, da realidade através da linguagem. A alteração do léxico e da 
sintaxe implica ou envolve uma alteração na maneira de compreender a realidade. Numa entrevista ele diz que "o seu método implica na utilização de cada palavra como se ela tivesse acabado de nascer" 4 , ou seja, ele não se interessa nos sentidos sedimentados das palavras mas nos sentidos novos, nas conotações criadas em cada uso das palavras e nas suas combinações na sintaxe. Isto é a capacidade de dar nova vida à linguagem, de revitalizar a linguagem, segundo a expressão de Eduardo Coutinho. Não é por acaso que Guimarães Rosa é um dos escritores transculturadores na opinião de Rama e esta revitalização da linguagem praticada também por Mia Couto aproxima o escritor moçambicano das posições dos transculturadores.

Também o uso de nomes próprios e topónimos com um significado que serve para caracterizar as pessoas ou os lugares é um recurso lingüístico usado por escritores transculturadores como Guimarães Rosa ou Juan Rulfo. Mia Couto também o usa neste romance e, por exemplo, o nome de Mwadia "queria dizer canoa em sinhungwé. Homenagem aos barquinhos que povoam os rios e os sonhos" (PS, p. 25) Através do significado do nome e da associação do seu nome com os livros Mwadia aparece como intérprete, como aquela que está a ligar os mundos do passado e o presente através da leitura dos documentos coloniais e a fazer a leitura do africano para o receptor colonial.

Mais uma prova que confirma a posição de Mia Couto relativamente ao uso da língua não ser uma posição de superioridade é o discurso crítico sobre o uso da língua que se apresenta no romance. $O$ poder associado ao uso da língua como instrumento de dominação colonial manifesta-se como possibilidade de manipulação das crenças e das mentalidades: Zero Madzero “aderira aos 'vapostori' apenas porque, para ele, o nome soava como um aportuguesamento da palavra pastores e não de apóstolos” (PS, p. 22). A mudança lingüística implica às vezes uma mudança nos valores e os costumes: "Aliás, desde os tempos da

4 Günter Lonrenz, "Diálogo com Guimarães Rosa”, em E. Coutinho, Guimarães Rosa, Col. Fortuna crítica, Rio de Janeiro, Civilização Brasileira, 1991, p. 66. 
Revolução que o velho Lázaro Vivo deixara de se apresentar como um nyanga. Ele era, agora, um conselheiro tradicional” (PS, p. 25). Trata-se de um processo de neoculturação: sob o novo termo "conselheiro" persiste a antiga ocupação de adivinho.

Mas o discurso crítico sobre o uso da língua mostra-se nomeadamente nas conversas entre o escravo Nimi Nsundi e a indiana Dia. Esta vai questionar o uso da língua portuguesa pelos padres em Moçambique: “-Pois eu não sei se faria uma traição dessas. Vocè sabe para que é que vai ser usada essa língua?” (PS, p. 71). Além disso, através das questões que coloca evidencia a posição de superioridade na que é situada a língua portuguesa relativamente à língua de Goa visto Nimi nem sequer ser consciente da existência dessa língua: “- E eu lhe pergunto, esteve todos esses anos em Goa, aprendeu alguma palabra na nossa língua? -Qual língua? Vocês têm uma língua?” (PS, p. $71)$.

Também essa diversidade das falas moçambicanas, isto é, a situação actual de heterogeneidade lingüística é ressalvada no romance através das dificuldades que Mwadia tem para perceber algumas expressões de Zero Madzero: “- Não vè que estou a fazer kukwenga? Fazer o quê? - Faço continência” (PS, p. 42), ou através do destaque do uso de determinadas falas em determinados momentos.

A maneira como a língua constrói a realidade vê-se no uso dos termos seguintes pelos portugueses do século XVI: "Chamavam de Torna-Viagem a este percurso da Índia para Portugal. E chamavam de Contra-Costa ao Oriente de África. Tudo fora nomeado como se o mundo fosse uma lua: de um só lado visível” (PS, p. 72). No entanto, uma das críticas que Mignolo realiza do conceito de transculturação de Ortiz e Rama é a seguinte:

Ele nunca levou a transculturação a esse nível de auto-reflexão. A transculturação fica lá -no enunciado e não no lócus de enunciação. A diferença fundamental entre a transculturação, por um lado, e a 'dupla consciência mestiza' e a créolité, por outro, pode ser observada precisamente no fato de que as últimas 
são todas palavras-chave que questionam o local universal e a pureza epistemológica do sujeito que conheces.

Esta possibilidade de levar a transculturação até o lugar de enunciação e a utilização de categorias de pensamento não occidentais pode ser rastejada no romance de Mia Couto. Assim, quando ele fala dos lugares de Vila Longe, descreve-os como se fossem um conglomerado de espaço e tempo, um espaço que só pode ser explicado apartir da passagem do tempo. Isto remete para algumas categorias de certas línguas bantus que definem simultaneamente o espaço e o tempo. Um exemplo no romance é a descrição da barbearia de Jesustino: "Tudo pousado, parado, em pasmo sobre o passado" (PS, p. 146) Por outro lado, também a visão metafórica da realidade, em oposição à visão lógica e causal do pensamento ocidental, está presente no romance: "Isto é você. Parece uma raiz. Mas é uma árvore que vive enterrada" (PS, p. 32).

\section{A estruturação literária}

Ángel Rama diz que as estruturas narrativas tradicionais elaboradas sobre o modelo do naturalismo do século XIX estavam muito afastadas das inovações introduzidas por Joyce, Virginia Woolf ou outros. Mas os transculturadores procuraram subverter os modelos narrativos aproveitando as novedades técnicas, mas apartir das estruturas clásicas ou tradicionais.

Rama analisa o procedimento usado por Guimarães Rosa em Grande Sertão: Veredas, isto é, a existência de um interlocutor que não aparece na narração embora a sua presença seja fundamental para justificar o relato do narrador. Estas observações de Rama sobre a maneira como Guimarães Rosa leva a oralidade à sua escrita são fundamentais para entender qual a forma de estruturação literária deste romance de Mia Couto. Trata-se também aqui de um fenómeno de neocultaração na estruturação literária de O outro pé da sereia. Por um

5 Walter D. Mignolo, Histórias locais/ Projetos globais.Colonialidade, saberes subalternos e pensamento liminar, Belo Horizonte, Editora UFMG, 2003, p. 233. 
lado, o romance tem uma estrutura que parece concordar com os modelos narrativos ocidentais: a narração constrói-se em dois tempos: 2002 e 1560. Os capítulos que acontecem no presente narrativo (2002) desenvolvem-se em Moçambique, na aldeia de Vila Longe e arredores. No entanto, impressos em páginas cor de marfim (na edição da Caminho) e com tipografia diferente, seguem-se, alternados com os outros, os capítulos que narram a travessia do oceano Índico em barco do missionário jesuíta Gonçalo da Silveira (personagem rigorosamente histórico, "mártir" do Cristianismo em terras de Moçambique) e de outros personagens, tais como o escravo Nimi Nsundi, ou o jovem padre Manuel Antunes, seduzido pela sensualidade africana. A mistura de duas histórias e dois tempos narrativos que convergem através da imagem da Virgem e da leitura dos manuscritos é característica do romance ocidental que joga com os tempos e as intersecções entre diferentes histórias. Também a divisão em capítulos e até o original recurso de introduzir uma outra cor para marcar os capítulos do tempo passado são recursos mais próprios de uma narrativa ocidental.

Contudo, o desenvolvimento das histórias tem mais a ver com as formas narrativas tradicionais africanas, isto é, tem mais a ver com a oralidade. As histórias desenvolvem-se através dos acontecimentos que o narrador e as personagens referem. No que diz respeito a este contar histórias, próprio da oralidade é que o interlocutor tem um papel fundamental, como em Guimarães Rosa. Trata-se de duas viagens: a de Mwadia que visa descobrir um lugar para proteger a Virgem e a viagem dos padres portugueses que visam evangelizar um território. Essas viagens, os obstáculos e a superação dos mesmos constituem a matéria narrativa. Isto é, trata-se de uma matéria narrativa tradicional, característica das narrações orais.

Também em $O$ outro pé da sereia estão excluídas a estrutura linear e o carácter autobiográfico enquanto a estrutura dialogal articula o romance todo - e a importância deste diálogo está marcada na tipografia pelas letras itálicas. As viagens são a matéria narrativa fundamental e também alternam nesta narrativa as histórias contadas 
e os provérbios. Aliás, a ambigüidade entre o real e o maravilhoso no romance tem a ver com esta estruturação híbrida entre a escrita moderna e a oralidade tradicional.

E também aqui, como acontecia com o uso da língua, apresentase no romance uma reflexão sobre a oralidade e a escrita. A mãe de Mwadia, Dona Constança apresenta-se como analfabeta para papéis. No entanto, ela sabe ler na areia: "-A senhora não disse que lia na areia? É verdade, é verdade. Nesse outro tempo o seu livro era o chão imenso, por aí fora. Quem lhe virava as páginas eram as estações do ano” (PS, p. 280). Mia Couto utiliza esta metáfora para falar do predomínio da oralidade sobre a escrita, mas também Constança fala do conhecimento da escrita como uma mentira, como uma invenção, isto é, está a questionar a predomínio que o pensamento ocidental atribui à escrita sobre a oralidade como fonte de legitimidade.

\section{Cosmovisão}

No âmbito da cosmovisão Ángel Rama salienta a influência nos escritores transculturadores da nova visão do mito introduzida pelos estudos antropológicos ou psicoanalíticos. Contudo, os escritores transculturadores superam estas interpretações do mito ao instalar-se num "pensar mítico".

No romance de Mia Couto também são os mitos que estruturam o relato e não só como conteúdo ou matéria narrativa, mas também como cosmovisão, como forma de pensar que articula as duas histórias e os dois tempos narrativos. Dois são os mitos fundamentais. O primeiro é o mito de Kianda a que alude Nimi Nsundi na primeira carta a Dia: "Os portugueses chamam isso de baptismo. Eu chamo de outra maneira. Eu digo que estou entrando em casa de Kianda. A sereia, deusa das àguas. É essa deusa que me escuta quando me ajoelho perante o altar da Virgem" (PS, p. 131). Este mito que remete para o sincretismo religioso articula o relato todo porque para Nimi Nsundi, como confessa numa outra carta a Dia, "é ela que está dentro da escultura da Virgem. Quando a olhei de frente confirme que era ela, a Kianda: os cabelos, a 
pela clara, a túnica azul. O que sucedeu é que a nossa deusa ficou prisioneira na estátua de madeira” (PS, p. 242). Essa libertação da deusa prisioneira na Virgem, do mito africano dominado pelo mito cristão, da cosmovisão moçambicana afogada pela mentalidade colonial é o objetivo fundamental do romance. No entanto, o resultado desta libertação não é uma recuperação da africanidade livre de qualquer influência cultural mas a confirmação dos processos de transculturação no nível da cosmovisão.

O segundo mito tem a ver com o primeiro e é aquele que Casuarino conta à brasileira. É este mito que possibilita a compreensão da personagem de Mwadia como adivinha ou como intérprete apartir do sonho da sua mãe quando ela nasceu. Assim, Mwadia é a canoa que faz a viagem entre o passado e o presente, entre o mundo dos mortos e o mundo dos vivos, entre a leitura dos manuscritos dos portugueses e as sessões de transe para os afroamericanos, entre a escrita e a oralidade, entre as línguas africanas e as línguas portuguesa e inglesa. Em definitiva, Mwadia é o personagem onde o conceito de neoculturação atinge a maior concretização.

São os resultados dos processos transculturadores nos níveis axiológico e ideológico que Mia Couto quer mostrar através do confronto entre os preconceitos dos afroamericanos sobre África e a realidade africana. Quando os afroamericanos chegam têm uma ideia prévia do que é a Àfrica autêntica: "Como Casuarino previra, os americanos ficaram fascinados com a sessão de transe. - Eis África autêntica, repetiam, deleitados” (PS, p. 276). Eles pensam que a autenticidade é aquilo que se adequa às teorias já feitas, aos preconceitos. Eles estão a pensar desde o pensamento ocidental, desde uma metafísica da identidade e da adequação que não permete que a diferença apareça, que rejeita tudo aquilo que não entra na grelha dos conceitos prévios.

A situação criada neste confronto entre os habitantes de Vila Longe e os afroamericanos possibilita olhar para a fusão das tradições e a modernidade e analisar quais os processos de deculturação, aculturação e neoculturação produzidos. 


\section{Conclusão}

Depois de ter analisado estes três aspectos fundamentais que caracterizam as narrativas dos escritores transculturadores, as conclusões no que diz respeito ao romance de Mia Couto são as seguintes: este romance partilha a maior parte das características que Rama definiu como próprias dos romances da transculturação narrativa no âmbito latinoamericano. A influência na escrita de Mia Couto de Guimarñaes Rosa, um dos grandes transculturadores segundo Rama, é fundamental no que diz respeito à língua e à estruturação literária. É o próprio escrito Mia Couto quem estabelece uma comparação entre o sertão do brasileiro e a savana africana oferecendo algumas das chaves da possibilidade de falar em transculturação também no contexto africano:

O sertão é, pois, um mundo em invenção. Tudo isto se pode dizer da savana, o espaço onde se constrói não apenas a paisagem de África mas onde África se constitui. O sertão e a savana são assim mundos construídos na linguagem. Nestes territórios o leitor é, ao mesmo tempo, viagem e viajante. Sendo muito caminháveis, esses territórios não são, contudo, espaços que se atravessa. O sertão de Rosa é a própria travessia. ${ }^{6}$

Mesmo assim, um dos objetivos deste trabalho era analisar quais os limites deste conceito de transculturação narrativa. Ao reflectirmos sobre o uso da língua já vimos algumas das críticas de Mignolo ao conceito e como é que o romance de Mia Couto consegue ir além da transculturação como conteúdo ou objeto de estudo e situar-se numa perspectiva na qual o lugar de enunciação é também um lugar de transculturação. Neste aspecto o personagem de Mwadia como representante dos processos de neoculturação e a aproximação do narrador deste personagem são fundamentais. Outra das críticas que recebeu o conceito de Rama foi a realizada por Friedhelm Schmidt. Segundo este pensador, Rama apresenta a transculturação como uma série de processos que acontecem nas culturas dominadas, mas

\footnotetext{
6 Mia Couto, Pensatempos, Lisboa, Caminho, 2005, p. 109.
} 
esquece quais as mudanças por causa do contato entre ambas as duas nas culturas dominantes. O romance de Mia Couto aborda também esta questão através dos personagens afroamericanos e da análise dos preconceitos que eles têm sobre a cultura africana e das mudanças que experimentam estes preconceitos ao serem confrontados com a realidade.

Alberto Moreiras realiza mais uma crítica ao conceito de Rama. Ele pensa que para Rama a transculturação é bem sucedida quando a cultura dominada consegue inscrever-se na cultura dominante. (referência?) Isto supõe a aceitação do domínio como inevitável e uma visão eurocêntrica. A situação que apresenta o romance de Mia Couto não se corresponde bem com esta descrição de Moreiras porque é uma situação de heterogeneidade, onde há alguns aspectos da cultura dominante que foram aceites e outros não e nem todos aceitam as mesmas coisas. Outra crítica de Mignolo é que as tradições e saberes das culturas indígenas ou africanas podem sobreviver independentemente do processo transculturativo. Esta perspectiva não assimiladora é partilhada por Mia Couto no romance ao falar, por exemplo, da diversidade das línguas que são faladas e dos rituais e costumes que são praticados pelos diferentes personagens do romance.

\section{Referências Bibliográficas}

\section{A. Bibliografia activa.}

COUTO, Mia. O outro pé da sereia. Lisboa: Caminho, 2006.

\section{B. Bibliografia passiva.}

AFONSO, Maria Fernanda. O conto moçambicano. Escritas pós-coloniais. Lisboa: Caminho, 2004.

CAVACAS, Fernanda. Mia Couto: Acrediteísmos. Lisboa: Mar Além, 2001.

COUTO, Mia. Pensatempos. Lisboa: Caminho, 2005.

FIGUEREIDO, Eurídice (Organizadora). Conceitos de literatura e cultura. Juiz de Fora: Editora UFJF, 2005.

LEITE, Ana Mafalda. Literaturas africanas e formulações pós-coloniais. Lisboa: Edições Colibrí, 2003.

LORENZ, Günter. Diálogo com Guimarães Rosa. In E. Coutinho, Guimarães Rosa, Col. Fortuna crítica. Rio de Janeiro: Civilização Brasileira, 1991.

MIGNOLO, Walter D. Histórias locais/ Projetos globais.Colonialidade, saberes subalternos e pensamento liminar. Belo Horizonte: Editora UFMG, 2003. 
RAMA, Ángel. Literatura e cultura na América Latina. São Paulo: Editora Universidade de São Paulo, 2001.

RAMA, Ángel, Transculturación narrativa en América Latina. Montevideo: Fundación Angel Rama, 1983. 